\title{
Crecer a pesar de todo: un caso de resiliencia infantil ${ }^{*}$
}

\author{
Nonetheless, Growing Up: A Children Resilience Case \\ Santiago Pérez Echeverri ${ }^{1}$
}

Para citar este artículo: Pérez, S. (2016). Crecer a pesar de todo: un caso de resiliencia infantil. Infancias Imágenes, 15(2), 239-252.

\section{Resumen}

Este artículo proviene de una investigación basada en el estudio de caso de un niño de 10 años de edad, con el aporte de los relatos que surgieron en el acompañamiento psicológico al que asistía regularmente. El objetivo consistió en evidenciar factores de resiliencia en los relatos recolectados mediante entrevistas clínicas, haciendo claras capacidades de adaptación en el niño que obedecen a su proceso de desarrollo. Todo esto teniendo en cuenta experiencias de separación y ambivalencia afectiva a lo largo de diferentes momentos de su vida hasta la actualidad, que motivan la participación en el acompañamiento psicológico. El proyecto se llevó a cabo desde un enfoque de investigación cualitativa de tipo descriptiva y mediante el uso de técnicas como el estudio de caso y la entrevista.

Palabras clave: relato, desarrollo del niño, estudio de caso, infancia.
Recibido: 23-mayo-2016 / Aprobado: 12-agosto-2016

\begin{abstract}
This article proceeds from a research based on the case study of a 10-year-old boy, with input from the stories that emerged in the psychological treatment which he attended regularly. The objective was to demonstrate resilience factors in stories collected through clinical interviews, showing of the children adaptation abilities which respond to his development. All this taking into account experiences of separation and emotional ambivalence throughout different times of his life until now, motivating participation in psychological support. The project was carried out from descriptive qualitative research approach using techniques such as case study and interview.
\end{abstract}

Keywords: stories, child development, case study, childhood.

\footnotetext{
* Artículo de investigación científica. Resultado de estudio de caso de acompañamiento psicológico a niño de 10 años de edad durante el año 2015 y primer semestre de 2016. Acompañamiento solicitado por la oficina de participación social de un Hospital Público de la ciudad de Bogotá y la familia del niño. La investigación se encuentra en la línea lenguaje, discurso y saberes de la especialización Infancia, Cultura y Desarrollo de la Universidad Distrital Francisco José de Caldas.

1 Psicólogo, Universidad Pontificia Bolivariana. Especialista en Infancia Cultura y Desarrollo, Universidad Distrital Francisco José de Caldas. Psicólogo de salud pública, ESE Hospital Pablo VI Bosa. Correo electrónico: sperezec@gmail.com.
} 


\section{Introducción}

"Crecer a pesar de todo" es una frase que hace referencia a una serie de experiencias del devenir profesional y la observación de historias de vida de personas con potenciales de cambio y crecimiento excepcionales. Con lo anterior me refiero a la resiliencia o a todo crecimiento que parece salirse de la norma teórica en la que se basan los profesionales de la salud o las ciencias sociales y humanas. Como profesional, me pregunté por ese crecimiento en los niños una vez graduado como psicólogo, porque frecuentemente me asombraba lo difícil que eran sus condiciones de vida y su capacidad transformadora por medio de la creatividad, el juego y el arte. De allí que me Ilamaran la atención los conceptos de entropía negativa, estudiado por Heunneus (1987), y el efecto Pigmalión, descrito por Gutiérrez (2010): ambos conceptos indican que los organismos vivos (en este caso seres humanos) a medida que crecen son más organizados, diferenciados del ambiente en que viven y que las expectativas sociales respecto a una persona pueden generar cambios en su comportamiento que contribuyen positivamente en su desempeño y desarrollo.

El estudio de caso desarrollado en el presente artículo tiene relación con las historias de vida y diferentes relatos del comportamiento de un niño que me generó esa misma sensación de fuerza transformadora en la infancia. Sin embargo, a diferencia de los cuestionamientos realizados hasta ahora, pude acercarme a este niño por medio de mí que hacer como psicólogo y en medio de las consultas observé sus maravillosas cualidades y el uso de ellas como estrategia. La resiliencia fue en esta investigación una categoría importante de estudio, por esto acudí a Boris Cyrulnik para ampliar teóricamente el concepto y entender mis observaciones al respecto de este niño: la resiliencia es "un proceso, un conjunto de fenómenos armonizados en el que el sujeto se cuela en un contexto afectivo social y cultural" (Cyrulnik, 212, 2001). Era una definición que me pareció relevante y me sigue haciendo figura aún después de realizar el estudio de caso, pues este niño, al que llamaré Juan, de 10 años de edad, vivió diferentes experiencias de separación afectiva de sus figuras cuidadoras y de la institucionalización como método restitutivo de derechos. Experiencias difíciles de sobrellevar y posibles focos de problemática en la conducta en el niño (esto último evaluado como psicólogo). Al mirar un poco más allá, me interesé en estudiar los aspectos positivos observados en el uso de recursos que le brindaba el contexto o que se observaban en su propia personalidad, como por ejemplo el talento por el dibujo, la evitación constante de emociones de tristeza e ira y su interés por la matemática y habilidades con los números. Los relatos de Juan en el espacio de consulta psicológica fueron fundamentales, al igual que sus dibujos. Estos permitieron el material de análisis y de estudio para la investigación. Entender la infancia es un reto para la psicología: constantemente se tienen claros los diagnósticos, los métodos y las técnicas terapéuticas, pero casi nunca se brindan estrategias humanas de atención a la infancia o cualquier grupo de edad en el espacio de consulta. Es un reto, tanto por la falta de estrategias como por el momento en que deben ser aplicadas o propuestas en el espacio de consulta para lograr procesos de crecimiento y transformación en el niño. Siempre, como profesional, tengo esa sensación de una infancia no "descubierta" que quiero conocer de una manera descentrada de las teorías y métodos conocidas como psicólogo. Larrosa (2000) explica que los niños nacen como nueva realidad que no se inserta en las ideas de temporalidad casusa-efecto o condición-consecuencia de la ciencia moderna. Por el contrario, representan a un otro que no es el objeto de investigación que creemos conocer, sino "la absoluta heterogeneidad respecto a nosotros y a nuestro mundo" (Larrosa, 5, 2000). Por esta razón, la escritura del artículo es una invitación a conocer el mundo del niño como sujeto, independiente de las teorías, más allá de las creencias y buscando el ser humano que se sienta frente a los ojos de un otro, como persona transformadora y creadora. El caso de Juan me permitía demostrarme cada vez más que la resiliencia era una posible cualidad más allá de los motivos de consulta o las técnicas empleadas en el espacio de entrevista clínica. Observé en el niño el uso de capacidades para responder a las experiencias presentes y demandas del medio familiar, social y educativo. 


\section{Marco teórico}

Como punto de partida, busqué investigaciones relacionadas con la infancia y la resiliencia. Descubrí que existe material investigativo relevante y diversas publicaciones que me permitieron entender que no era un tema precisamente nuevo, que podría contribuir a un campo del conocimiento reafirmando algunos hallazgos y que el relato sería una de las maneras más humanas de acercarme al niño. Tres de ellas llamaron mi atención por el uso de métodos, el uso de instrumentos y tipo de población participante: Resiliencia en niños con experiencias de abandono (Obando, Villalobos y Arango, 2010), La resiliencia en niños institucionalizados y no institucionalizados (Gianino, 2012); Estudio de casos sobre factores resilientes en menores ubicados en hogares sustitutos (Castañeda y Guevara, 2005). De acuerdo a la búsqueda realizada, pude definir tres hallazgos importantes: 1 ) se demuestra la presencia de características o actitudes resilientes en niños con antecedentes de abandono o diversas experiencias de vulnerabilidad; 2 ) la resiliencia no solo se relacionada con capacidades individuales, también con interacciones del espacio social, cultural o institucional a los que pertenece el niño, y 3 ) el espacio institucional (en niños bajo medida de protección) continúa siendo un factor de soporte externo que facilita el desarrollo de la resiliencia.

Un segundo punto importante que determinó el desarrollo del estudio fue la profundización en el concepto de resiliencia. A medida que lo estudié fue posible descubrir tres condiciones para la resiliencia en un niño:

$1^{\text {a }}$ condición. Los recursos internos: son algunos aspectos de personalidad que el autor define como temperamento. Entre ellos se encuentran las estrategias o capacidades del niño, como, por ejemplo, los factores de personalidad, pues se consideraría para un caso así una relación directa entre temperamento y personalidad. Cyrulnik (2001) habla sobre ello y define que el niño resiliente se hace dos preguntas iporque tengo que sufrir tanto? y ¿cómo voy a hacer para ser feliz de todos modos? Ambas preguntas hablan de mecanismos fundamentales (que consideraría factores de resiliencia): uno es la racionalización o intelectualización del problema y el otro es la imaginación que invita a soñar. Este condicionamiento es intimo (de temperamento), cuando encuentra una mano tendida la evolución de los niños no es desfavorable, por el contrario, facilita el proceso de resiliencia.

$2^{a}$ condición. La significación que se le atribuye al hecho: hace referencia a la percepción o configuración de trauma en la experiencia del niño. Cyrulnik (2006) refiere que son los niños los más afectados por la violencia política y la guerra. $\mathrm{Si}$ vamos a un caso particular, es preciso que el niño o la persona relate de manera personal su historia, en pasado. Esto no quiere decir que solucione su trauma, pues la interpretación que tenga el tercero puede orientar la narración a un trastorno duradero o a la integración de la herida a una personalidad del sujeto. El trauma se constituye por la relación entre la sensación de culpa por los hechos ocurridos y el espanto de la sensación real.

$3^{\text {a }}$ condición. Disposición de recursos externos: el sujeto que ha sido tocado por un hecho que le hiere no tiene oportunidad de retomar su vida si no hay alrededor de él o ella alguien que le tienda la mano. Llámese hombre, familia, mujer, mamá, barrio, amigos, etc. Al respecto, Cyrulnik (2006) resalta la importancia del vínculo afectivo en la infancia, pues en ausencia del mismo los niños y niñas no se socializan de forma eficiente y mueren o, si, por el contrario, logran abrirse camino y vivir se fijan a pequeños hilos de resiliencia que los conducen a la delincuencia o psicopatía: "suficiente para sobrevivir, pero no para socializarse" (Cyrulnik, 119, 2006). Solo un porcentaje muy inferior de niños sin relaciones vinculares iniciales, logra abrirse camino a la socialización efectiva gracias al encuentro de otras figuras significativas (manos tendidas) y un temperamento particular.

Una vez culminada la búsqueda y afianzadas las teorías, el paso siguiente fue inscribir el proceso de investigación en un marco referencial investigativo o línea investigativa llamada Lenguaje, Discurso y Saberes, en el marco de la Especialización infancia Cultura y Desarrollo de la Universidad Distrital. Karina Bothert, docente e investigadora, aceptó el estudio de caso como parte de la línea y decidió acompañar el proceso. En esta línea de investigación existe una posición ética y política de escucha 
del investigador hacia los discursos y narraciones del niño o niña como principal protagonista de su historia.

En consecuencia, la investigación se fundó en una pregunta que motivó el desarrollo de objetivos y conclusiones: ¿qué factores de resiliencia se pueden evidenciar en los relatos de vida y otras narrativas de un niño?2

\section{Metodología}

Comencé a realizar el proceso metodológico a partir de unos enunciados teóricos arrojados principalmente por el problema de investigación y la pregunta. Además del marco en que se inscribe el proyecto tanto desde la línea de investigación como desde la misma especialización en Infancia Cultura y Desarrollo. Definí entonces unas categorías teóricas globales: infancia, cultura y desarrollo. Por otro lado, unas categorías teóricas específicas como resiliencia, relatos y saberes infantiles. Esta diferenciación obedece a la organización que, como investigador, hice para determinar el origen de las categorías: las globales son sugeridas por el marco de la especialización en Infancia, Cultura y Desarrollo; mientras que las específicas por el tema particular de la investigación en la que se pretende identificar aspectos resilientes en los relatos del niño.

La investigación se centró en el estudio de caso de Juan y la recolección de diferentes relatos durante el acompañamiento clínico tanto del niño como de otras figuras significativas como insumo de análisis para el estudio de caso. Como principal participante de la investigación se encuentra Juan, con 10 años de edad, quien reside con su madre biológica (María) y la pareja de ella (Marcos). El niño ha presentado diferentes comportamientos que motivan la solicitud de un profesional de psicología para que acompañe el proceso de adaptación y conducta. Este proceso se desarrolló en el marco de la gestión institucional de la oficina de participación social de un hospital público de la ciudad de Bogotá.

El proyecto se llevó a cabo desde un enfoque de investigación cualitativa de tipo descriptiva. El

\footnotetext{
También me pregunté por los relatos de otras personas significativas
} para el niño. estudio de caso, la entrevista y la observación fueron las técnicas empleadas para el entendimiento de los relatos del niño participante y demás figuras significativas.

La elección del estudio de caso como técnica no desconoce que aún existen ambivalencias en su uso como técnica o como enfoque. Es decir, que los investigadores lo aplican de las dos maneras, dependiendo de la orientación en la pregunta y del problema de investigación. De acuerdo con Cerda (2007), el estudio de caso en el contexto psicológico es la recolección de datos de una persona y del ambiente que le es propio, en el que se describen aspectos, por ejemplo, familiares, sociales y personales. Incluso, muchos hallazgos a partir del estudio de caso (como técnica) han permitido el descubrimiento de teorías generales del comportamiento y el desarrollo psíquico de los sujetos y la sociedad.

La entrevista como técnica es empleada en el contexto investigativo por lo general de manera estructurada o no estructurada, podría decir que, para el presente proyecto, la segunda (de tipo no estructurada) tiene mayor relación con el proceso de entrevista clínica en que se desarrollan los acompañamientos psicológicos al niño y sirve como base para el estudio de los relatos. En el contexto de la consulta psicológica, la entrevista clínica designa, en primer lugar, un procedimiento donde el terapeuta se deja, por lo menos en parte, guiar por las intervenciones del paciente. Se trata de una entrevista no dirigida, como en una entrevista de investigación de cohorte cualitativa, el cual es un género heterogéneo (existen numerosos tipos de entrevista clínica que varían según diferentes dimensiones, en particular, varían de acuerdo al grado de estructuración de la entrevista) pero, más allá de ello, tiene por característica principal reposar sobre asimetrías de estatuto y de roles de los interlocutores y de su posición frente a eso que se dice (Salazar Orvig, 1998).

Por otro lado, la observación es tomada como instrumento de la etnografía: respecto a ella, Guber (2001) refiere que puede acompañar las entrevistas y acercamientos del investigador porque nutre el proceso de participación y de investigación. 


\section{Análisis de relatos}

Este proceso se resume en la organización de los diferentes relatos, tanto del niño como principal protagonista como de otras figuras significativas (docentes, orientadoras, madre biológica, talleristas grupo de participación social, etc.). Para la elección de dichos relatos se tomaron las historias clínicas que hasta el momento el investigador (psicólogo) tenía del caso. En este acompañamiento psicológico se observó que el niño participaba de un grupo de liderazgo, educación no formal de niños y adolescentes para el desarrollo de competencias y habilidades sociales que Juan valoraba positivamente; el colegio era otro de sus espacios sociales de encuentro altamente significativo. En dichos ámbitos ya se habían realizado entrevistas a orientadoras, docentes y acompañantes para conocer diferentes aspectos de personalidad o de comportamiento de Juan.

El siguiente paso fue organizar esos relatos alrededor del niño participante en categorías observadas. Se consolidó una matriz de la siguiente forma:

En una primera columna llamada categorías se asignaron enunciados de acuerdo a los relatos evidenciados previamente. En dicha columna se buscó dar lugar a la teoría de resiliencia desarrollada en el marco teórico, agregando además otras categorías a partir de la recolección de relatos. Ellas serían: familia e interacciones, grupo de participación social, aspectos de personalidad, motivos de consulta y rupturas familiares. Todas ellas en relación con los relatos producidos.

En una segunda columna (relatos y narrativas), se citan los relatos tanto de Juan como de los demás actores que compartieron sus experiencias con el niño y las dieron a conocer para el proceso de análisis Juan, María —mamá-, la trabajadora social y la coordinadora del grupo de participación social y docente de grado $5^{\circ}$ ).

En tercer lugar, la columna análisis y consideraciones contiene las observaciones realizadas por el investigador, tanto en lo descriptivo como en lo interpretativo mediante la teoría estudiada hasta el momento y el conocimiento de los relatos del niño y de los demás actores que participaron del proceso de recolección de información sobre él.

Tabla 1. Matriz de categorías, relatos y análisis del investigador.

\begin{tabular}{|c|c|c|}
\hline Tema & Relatos y otras narrativas & Análisis y consideraciones \\
\hline \multirow[t]{2}{*}{$\begin{array}{l}\text { Familia e } \\
\text { interacciones }\end{array}$} & $\begin{array}{l}\text { Juan: Con mi mamá es con la } \\
\text { que más estoy }[\ldots . .] \text { a veces veo } \\
\text { a mi abuela, allá siempre hay } \\
\text { primos }[\ldots] \text { hace mucho no veo } \\
\text { a mi abuela, porque mi mamá } \\
\text { no me ha vuelto a llevar [...] } \\
\text { mi padrastro se llama marcos, } \\
\text { él vive en la casa... mi papá } \\
\text { (Camilo), a veces él me visita, él } \\
\text { vive lejos, no sé dónde, con otra } \\
\text { persona [...] yo juego con mis } \\
\text { primos, pero cuando voy donde } \\
\text { mi abuela, ellos son más grandes. }\end{array}$ & $\begin{array}{l}\text { El campo de relaciones familiares del niño puede ser amplio, sin embargo, } \\
\text { se ve limitado por conflictos y tensiones entre su mamá y el resto de familia } \\
\text { extensa. El niño ha cambiado de diferentes figuras de crianza y autoridad a lo } \\
\text { largo de su desarrollo, por lo tanto, reconoce una familia amplia y extensa en la } \\
\text { que participan primos, abuelos, padre biológico, padre de crianza y su mamá. } \\
\text { De esta manera, Juan se afilia a diferentes personas como recurso interno para } \\
\text { sortear diferentes necesidades para su propio beneficio. Si vemos el dibujo de } \\
\text { la familia (figura 1) se puede corroborar esta información. }\end{array}$ \\
\hline & & $\begin{array}{l}\text { Figura 1. Dibujo de la familia. } \\
\text { Juan reconoce la autoridad de su madre. En este relato Juan demuestra que } \\
\text { tiene gusto por el espacio educativo, porque lo disfruta, tiene sus relaciones } \\
\text { sociales más estables hasta el momento (pues en otros relatos evidencia que no } \\
\text { tiene más amigos que los de su colegio). El ambiente educativo es un segundo } \\
\text { espacio de estimulación para el niño que le permite vivir aprendizajes diferentes } \\
\text { a los que vive en casa o frente a cualquiera de sus figuras de autoridad a lo largo } \\
\text { de su desarrollo. El colegio es significativo para Juan. }\end{array}$ \\
\hline
\end{tabular}


- Mmm, antes de venir para aquí estaba tratando de salir rápido de la casa, mi mamá me dejó el desayuno servido [...] tenía que lavar los platos, pero el plato de plástico se me cayó al piso, se quebró solo un poquitico [...]. Pues, no se dañó, solo fue un rotico pequeño. ¿Y usted para que necesita a mi mamá? -Para hablar con ella, así como hablo contigo. _ ¿ Usted le va a contar lo del plato? — No, eso se lo tienes que contar tú. - ¿ Y usted no podría hacerlo? -No. ¿Para qué quieres que lo haga? -Para no sentirme mal. - ¿YY qué crees que va a pasar? - No sé, no lo sé. - ¿Te van a pegar? —No lo sé.

Juan: [...] Mami es que te quiero contar algo. María: Y, ¿qué pasó Juan, ya que me va a decir?... Juan: Es que se me rompió el plato de plástico, yo iba a lavarlo [...]. María: Si ve, no me diga. En la casa no se puede comprar nada, porque no dura, él bota todo, o lo desaparece, lo daña [...]. A él no le dura nada [...]. Vea, por ejemplo, yo le compré unos colores y ayer le revisé y ya había botado dos, cuando le pregunté me dijo: '¿qué?, ¿colores? No sé mami, yo pensé que ahí estaban todos'. Y así, él va desapareciendo las cosas. [...]. Juan: Mami, es que yo creo que no se dañó del todo, es solo un rotico chiquitico, se puede utilizar [...]. María: ¿Sí? Yo ya no puedo estar comprando más cosas para la casa, porque él las daña. Vea, por ejemplo, la vajilla que teníamos hace unos días se fue dañando toda y por eso le compré unos platicos de plástico, pero también los daña $[\ldots]$.

Juan: Fueron muchas personas, mi abuela estuvo ahí. Marcos y mi mamá me acompañaron a la iglesia y en mi casa hicieron una fiesta, fueron 14 personas [...] bailé el ras tas tas $[\ldots]$. ¿Quiere ver las fotos? [...]. Ese día me dieron regalos y plata, Marcos me regaló cinco mil $[\ldots]$.
La relación de Juan con su madre es percibida positivamente por el niño. Sin embargo, para el caso de Juan, un vínculo protector que se ha visto interrumpido por demandas familiares e institucionales se ve revestido de la ansiedad o el temor ante una nueva separación. Esto, por ejemplo, hace parte del carácter o personalidad de Juan, pues en él se evidencia ansiedad y preocupación ante los comportamientos no deseados por sus figuras de autoridad, hace un esfuerzo muy alto por cumplir con sus demandas y le cuesta aceptar errores o dificultades de su propio comportamiento, pues mantenerse en una estructura básica que le provee seguridades (como el acompañamiento de su madre) es fundamental para su bienestar afectivo y metas de desarrollo. Además, evita o niega (como lo mencioné en párrafos anteriores) toda posibilidad de volver a vivir la experiencia de abandono y separación: esta misma característica se observa en otros relatos posteriores).

Continuando por la misma línea (pues el relato es amplio), se puede evidenciar de nuevo el llamado de atención de su madre, muy similar al que sucede en los relatos anteriores. Esta interacción sucede en presencia del investigador a quien el niño tiene oportunidad de abordar y le pide ayuda antes de la llegada de su mamá: " ¿Usted le va a contar lo del plato? [...] ¿Y usted no podría hacerlo? [...]". El investigador se niega y el niño toma la decisión de hacerlo, lo cual desencadena en el castigo (verbal) y la crítica negativa por parte de su madre. Sin embargo, en dicha interacción vuelve a surgir la negación (Cyrulnik, 2006) como característica defensiva en Juan, quien argumenta: "Mami es que yo creo que no se dañó del todo, es solo un rotico chiquitico, se puede utilizar [...].". Sobre esta característica Cyrulnik argumenta que la metamorfosis del dolor es una meta movilizada por mecanismos de defensa que le son costosos al niño $(31,2006)$. la negación y la huida hacia adelante son dos mecanismos defensivos fundamentalmente resilientes, el primero para brindar sensación de seguridad y el segundo para evitar la repetición de un evento que le cause malestar (Cyrulnik, 31, 2006).

En este relato el niño manifiesta su entusiasmo ante la celebración de su primera comunión. Entre los invitados se encontraba su familia extensa, lo cual el niño expresa con entusiasmo. Usa los recursos (función económica) que le provee Marcos y reconoce aspectos positivos del apoyo económico que le dio durante la celebración. Juan tiene una capacidad de afiliarse a recursos positivos para el beneficio de sus necesidades, que pueden ser económicas, afectivas o recreativas. Esta es una de las disposiciones temperamentales de la personalidad de Juan que sorprende, que estaría asociada a su característica resiliente de transformación (Cyrulnick, 2003). 


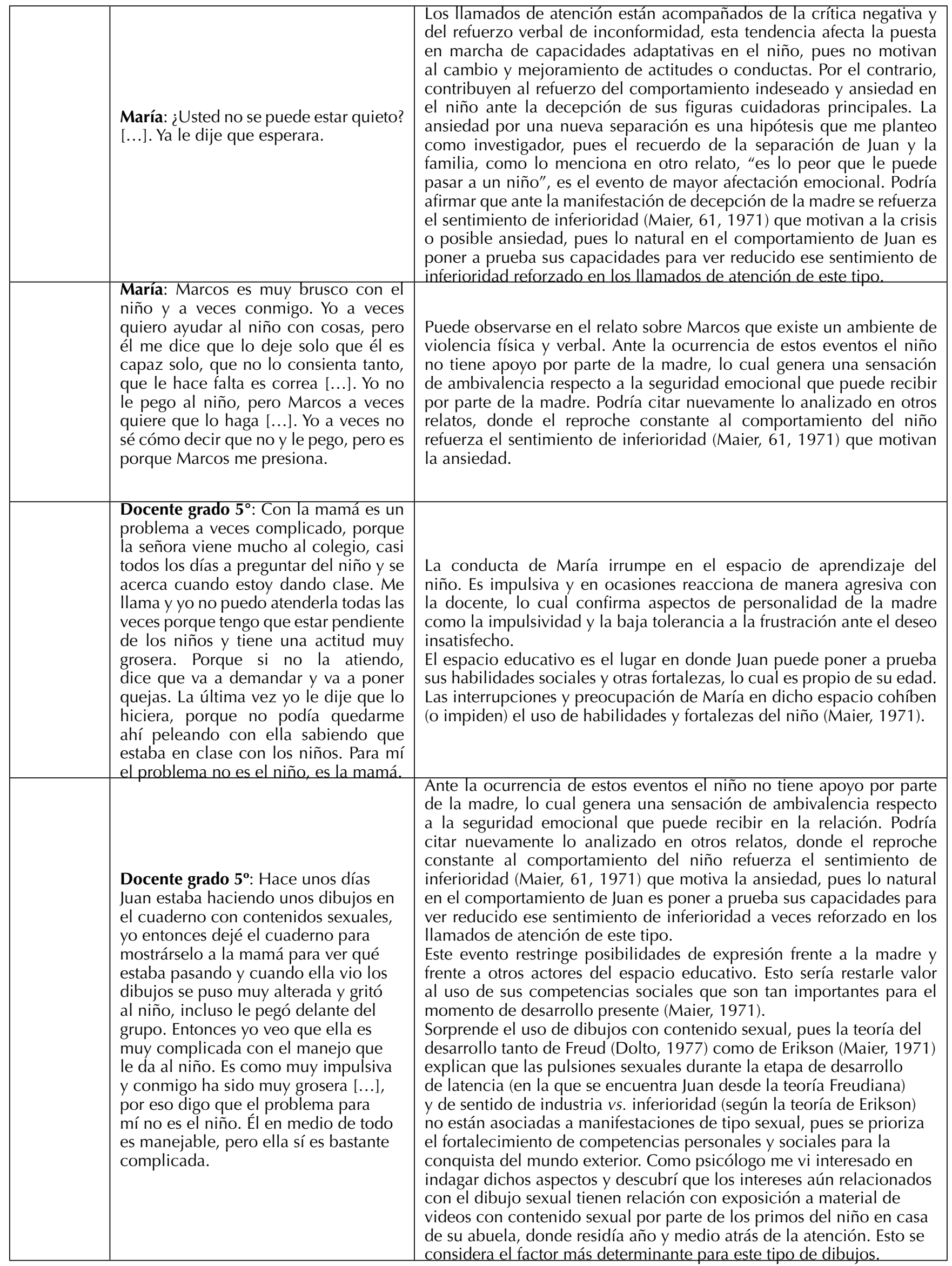




\begin{tabular}{|c|c|}
\hline $\begin{array}{l}\text { Grupo de } \\
\text { participación } \\
\text { social. }\end{array}$ & $\begin{array}{l}\text { Juan: A mí lo que me gusta del grupo es que } \\
\text { puedo aprender cosas que en el colegio no. }\end{array}$ \\
\hline & $\begin{array}{l}\text { Coordinadora grupo de participación: Un día } \\
\text { estábamos haciendo una actividad con los niños } \\
\text { en la biblioteca. Ese día estábamos hablando un } \\
\text { poco de derechos de los niños, ese era el tema } \\
\text { que estábamos trabajando. Entonces Martha } \\
\text { (coordinadora de la biblioteca) estaba conmigo. } \\
\text { Lo que hicimos fue mostrar unos videos y unas } \\
\text { imágenes que mostraban derechos de los niños } \\
\text { y las niñas [...] ya después conversamos un } \\
\text { poco con ellos sobre qué pensaban de uno y } \\
\text { otro derecho, cada niño iba hablando del tema. } \\
\text { Todos participaron con unas opiniones de lo que } \\
\text { ellos consideraban como un derecho. Los niños } \\
\text { decían cosas normales en las que no Ilamaba } \\
\text { mucho la atención lo que decían. Luego hicimos } \\
\text { como un sociodrama en el que se hacía una } \\
\text { pregunta reflexiva: ¿qué pasaría si nos faltara uno } \\
\text { de estos derechos? (educación, familia, atención } \\
\text { en salud, etc.). Los niños debían presentarlo por } \\
\text { medio de una actuación o por participación } \\
\text { verbal. Nosotras pusimos algunos ejemplos de } \\
\text { lo que podían hablar o decir. Cuando Juan quiso } \\
\text { participar habló sobre el derecho a tener una } \\
\text { familia. Él dijo: "Yo sí sé lo que es no tener la } \\
\text { familia, porque a mí me abandonaron cuando } \\
\text { tenía cuatro años en el Bienestar Familiar y es } \\
\text { lo peor que le puede pasar a un niño [...]". } \\
\text { Ya después nosotras nos quedamos plop, los } \\
\text { niños quedaron muy callados y Juan siguió } \\
\text { haciendo otras cosas, como si no hubiera dicho } \\
\text { nada. Nosotras seguimos y empalmamos la } \\
\text { intervención de Juan con la de otro niño [...] no } \\
\text { supimos cómo más manejar la situación". }\end{array}$ \\
\hline
\end{tabular}

Trabajadora social grupo de participación social (actividad en biblioteca): Al finalizar los talleres del grupo, los padres llegan sobre las cinco a recoger a sus niños. María llega a recoger a Juan un poco antes de la hora de salida, por parte de la coordinación del grupo se le permitía ingresar al taller, la actitud de Juan cambiaba con la presencia de ella. Él quería contarle lo que ha trabajado, ella intenta involucrarse en la actividad de una manera negativa, cuestionando a Juan por lo que hace, el niño se baja de nota. Al finalizar el taller ella le gritó un poco fuerte delante de los niños por hablar a destiempo [...] tanto que los mismos niños al final evaluaron la actividad y me mencionaron ese tema [...], ellos decían que a Juan como que lo trataba muy mal la mama. Por parte, de la coordinación del grupo se le solicita María llegar a las cinco o esperar afuera al niño, para que no afecte el desarrollo de Juan en los talleres del grupo de participación social.
El espacio educativo no formal del grupo de participación social al que asiste regularmente es relevante para Juan. Al igual que en el colegio, allí puede poner en práctica sus habilidades personales y encontrarse con diferentes pares con quienes puede compartir experiencias y percepciones, lo cual es natural dado el momento de desarrollo de industria vs. inferioridad (Maier, 1971). Lo diferente de este espacio radica en que lo aprovecha para el uso de otros beneficios personales diferentes a los que usa en el colegio, por ejemplo, refiere: "puedo aprender cosas que en el colegio no"

A pesar de la capacidad de negación y evitación en Juan, relata la experiencia de separación afectiva a inicios de su infancia. En este caso, es relevante que el niño se vale de espacios de confianza en los que no se siente evaluado ni presionado, por el contrario, le motiva a mencionar: "yo sí sé lo que es no tener la familia, porque a mí me abandonaron cuando tenía cuatro años en el bienestar familiar y es lo peor que le puede pasar a un niño [...]". Este ejercicio de compartir el relato contribuye a una organización de su propia experiencia y a una interacción que disminuye la carga emocional del mismo, pues sus palabras son claras y cargan la contundencia de una experiencia de un alto impacto emocional en su vida. (Bruner, 2013; Santamaría y Bothert, 2011).

El proceso de participación de Juan en este espacio social marca una relevancia para la experiencia de cambio, pues la invitación a participar se convierte en un apoyo del medio que sirve como mano tendida y recurso para metamorfosear la experiencia negativa de la cual fue objeto. Bien lo menciona Cyrulnik $(36,2006)$ al aclarar que para lograr el proceso resiliente es necesario tanto unos recursos internos y conductuales como una efectiva disposición de recursos externos sociales y culturales. Podría afirmar que la oficina de participación ha contribuido como recurso externo para estimular cambios en este niño que, ante la ausencia de unos oídos sensibles para escuchar sus relatos, fue capaz de ver en este espacio una oportunidad de transformar su experiencia.

Es repetitivo el estilo correctivo usado por María ante el comportamiento de Juan, claramente esto evidencia un tipo de relación en el que hay una tensión constante y las claridades de comportamiento pueden modificarse de acuerdo con el estado de animo de María, que fluctúa entre el castigo físico o verbal y un discurso en el que manifiesta deseos de cambio. Maier, al citar a Erikson, refiere que el niño posee un sentimiento de inferioridad por la edad y por la dependencia de la cual es objeto $(61,1971)$, no obstante, los trata de resolver usando diligentemente todas sus capacidades en el aprender haciendo y el uso de potenciales. De acuerdo con lo citado, la relación con la madre ofrece una ambivalencia: por un lado, el niño valora la compañía y el soporte de funciones del contexto familiar, por otro lado, el refuerzo de un sentimiento de inferioridad que dificulta constantemente el uso de oportunidades. 


\begin{tabular}{|c|c|c|}
\hline \multirow[t]{3}{*}{$\begin{array}{l}\text { Aspectos de } \\
\text { personalidad }\end{array}$} & $\begin{array}{l}\text { Docente } 5^{\circ} \text { : El niño es manejable, aunque es } \\
\text { un niño que siempre llama la atención, siempre } \\
\text { sucede algo cada día, puede ser que se le estalló } \\
\text { la lonchera, el yogurt o que se cayó de la silla. } \\
\text { Mire nada más la semana pasada le dije que se } \\
\text { sentara bien, porque lo vi muy mal sentado en } \\
\text { la silla y más tardecito se cayó hacia atrás y se } \\
\text { golpeó la cabeza. Si vamos a hacer una actividad } \\
\text { el comienza a preguntar que quien le tiene los } \\
\text { lápices, entonces siempre hay que dedicarle un } \\
\text { tiempo a Juan para poder comenzar a hacer las } \\
\text { cosas [...] eso no entiendo porque pasa, solo sé } \\
\text { que pasa y uno trata de enseñarle y él le coge } \\
\text { la idea, pero al siguiente día, es como si la } \\
\text { hubiera olvidado. Como si le hicieran falta esas } \\
\text { costumbres que apenas uno trata de enseñarles } \\
\text { a niños de } 1{ }^{\circ} \text { : de sentarse bien o de cuidar } \\
\text { los objetos o útiles escolares [...]. Con Juan } \\
\text { siempre está pasando algo, y todo parece ser } \\
\text { por descuido, aunque yo creo que él se puede } \\
\text { manejar en clase, no es mucho el problema, una } \\
\text { vez se le pone atención ya él se concentra. } \\
\text { Él es muy bueno para las clases de matemáticas, } \\
\text { todos los ejercicios los hace, siempre quiere } \\
\text { terminar de primero. Y sé que el dibujo también } \\
\text { le gusta mucho, generalmente con las tareas y los } \\
\text { contenidos de las materias no tiene problemas. }\end{array}$ & $\begin{array}{l}\text { Juan requiere de una atención especial, tanto en tiempo } \\
\text { como en instrucción, pues sus competencias atencionales } \\
\text { no le permiten concentrarse fácilmente. Cuando digo } \\
\text { atención especial, me refiero a una atención sensible y } \\
\text { cargada de afecto que facilite el uso de competencias, } \\
\text { un ejemplo de ello es lo que menciona la docente: "[...] } \\
\text { con Juan siempre está pasando algo, y todo parece ser } \\
\text { por descuido, aunque yo creo que él se puede manejar } \\
\text { en clase, no es mucho el problema, una vez se le pone } \\
\text { atención ya él se concentra". } \\
\text { La pérdida de objetos y el posible retroceso en aprendizajes } \\
\text { de adaptación social y atencional son producto del } \\
\text { cambio de roles parentales e inestabilidad en el proceso } \\
\text { de estimulación. } \\
\text { La intelectualización y la creatividad son dos factores de } \\
\text { resiliencia fundamentales en el niño, pues ambos generan } \\
\text { motivaciones en Juan, tanto por el lado de las ciencias } \\
\text { exactas como por el dibujo y el arte (esto observado en } \\
\text { los relatos). Juan recibe de ambas pasiones refuerzos } \\
\text { positivos que facilitan percepción de dominio y seguridad } \\
\text { personales para la superación tanto del sentimiento de } \\
\text { ansiedad e inferioridad de la etapa de desarrollo como de } \\
\text { las experiencias de vulnerabilidad. Son recursos para la } \\
\text { metamorfosis tanto de la presión del medio como de la } \\
\text { experiencia vivida. }\end{array}$ \\
\hline & $\begin{array}{l}\text { Juan: } M m m \ldots \text { no me gusta dibujar personas ni } \\
\text { familias }[\ldots] \text {. Además, yo solo dibujo en hojas } \\
\text { cuadriculadas }[\ldots] \text { no, porque esas hojas blancas } \\
\text { no me gustan casi }[\ldots] \text { no sé dónde están }[\ldots] \text { yo } \\
\text { los dibujé como a mi familia. }\end{array}$ & $\begin{array}{l}\text { La negación siempre es un mecanismo de defensa inicial } \\
\text { en Juan. A pesar de su capacidad imaginativa y el gusto por } \\
\text { el dibujo se niega a cumplir una instrucción externa, que } \\
\text { posteriormente hace y describe sin dificultad. Este proceso } \\
\text { que consiste en negar y luego permitir está asociado al } \\
\text { proceso de adaptación a la norma y autoridad considerado } \\
\text { generalmente como negativo. Ya se ha observado en } \\
\text { relatos previos y para el proceso investigativo y teórico } \\
\text { revisado puede inferirse que esta negación constituye } \\
\text { una alternativa de huida y de adaptación que en inicio es } \\
\text { evitativa, pero que en términos adaptativos le permiten al } \\
\text { niño sacar provecho positivo de la experiencia negativa } \\
\text { del dolor. Esto podría considerarse un factor importante } \\
\text { de personalidad contribuyente el proceso de resiliencia } \\
\text { en Juan que en el espacio de conclusiones podrá verse } \\
\text { ampliado. }\end{array}$ \\
\hline & $\begin{array}{l}\text { Juan: A mí me gusta jugar. En el colegio hay tres } \\
\text { amigos con los que juego más. Por la casa no } \\
\text { tengo casi amigos, solo los del colegio [...]. Las } \\
\text { materias que más me gustan son matemáticas y } \\
\text { ya. Me gusta mucho dibujar, por ejemplo, dibujo } \\
\text { también me gusta mucho [...]. En las tardes veo } \\
\text { televisión, veo Bajo Terra, Steven Universe me } \\
\text { parece chévere. ¿Usted lo ha visto? Lo dan por } \\
\text { Disney a las tres de la tarde [...] yo siempre } \\
\text { llego a la casa y almuerzo, después veo Steven } \\
\text { Universe y Bajo Terra, ya después hago tareas } \\
\text { [...]. A veces mi mamá me da plata para ir al } \\
\text { internet: entro a Facebook, juego y chateo, y ya. } \\
\text { Hablo con Marlon, que es un amigo del colegio, } \\
\text { también tengo otros dos amigos [...]yo hago las } \\
\text { tareas solo, mi mamá a veces me revisa, pero yo } \\
\text { las hago solo. Yo no pierdo materias, a veces me } \\
\text { regañan, pero no me va mal con las tareas, yo } \\
\text { me porto bien [...] yo siempre me porto bien. }\end{array}$ & $\begin{array}{l}\text { En el relato se combinan intereses con otros aspectos de } \\
\text { personalidad como la imaginación y fantasía que están } \\
\text { presentes en el dibujo como hobby y las caricaturas de } \\
\text { las que habla. La manifestación positiva de su propio } \\
\text { comportamiento, justo al final del relato, es común } \\
\text { en el discurso de Juan. En general las cosas están bien, } \\
\text { independiente de las condiciones del contexto, por } \\
\text { ejemplo: "Yo siempre me porto bien". Este tipo de relatos } \\
\text { han sido mencionados en otras ocasiones: "Mami es que yo } \\
\text { creo que no se dañó del todo, es solo un rotico chiquitico, } \\
\text { se puede utilizar [...]". Estos relatos citados evidencian } \\
\text { la negación y la huida hacia adelante como mecanismos } \\
\text { defensivos fundamentalmente resilientes, el primero para } \\
\text { brindar sensación de seguridad y el segundo para evitar la } \\
\text { repetición de un evento que le cause malestar (Cyrulnik, } \\
31,2006 \text { ). }\end{array}$ \\
\hline
\end{tabular}




\begin{tabular}{|c|c|c|}
\hline & $\begin{array}{l}\text { "Cuando haces algo malo }[\ldots . .] \text { ". } \\
\text {-Yo trato de olvidarlo, pues, la otra opción es } \\
\text { hacerles caso, porque quedan muy furiosos [...]. } \\
\text { Yo ya aprendí a hacer caso. Si quiere pruébeme } \\
\text { [...] las personas creen que yo soy cansón }[\ldots] \text {...]. } \\
\text { Pues cambio. - Pues: ¿Que quisieras cambiar? } \\
\text {-No, no quisiera cambiar nada más. Ya cambié } \\
\text { harto...yo voy a tratar de dejar de hablar tanto, } \\
\text { porque hablo mucho. - ¿Qué quieres cambiar } \\
\text { Juan? No, nada. Yo quiero cambiar [siguiendo } \\
\text { la misma conversación, Juan argumenta que el } \\
\text { asiste al psicólogo para "cambiar cosas"]. - ¿Y } \\
\text { cambiar qué cosas Juan? -No sé, todo. }\end{array}$ & $\begin{array}{l}\text { Juan reconoce que hace esfuerzos por olvidar las presiones } \\
\text { de cambio que le demanda el contexto social al que } \\
\text { pertenece. También hace un esfuerzo por equilibrar las } \\
\text { demandas externas con las internas, movilizadas por sus } \\
\text { propios intereses y deseos. Esta ambivalencia es producto } \\
\text { del momento de desarrollo que ya he citado previamente, } \\
\text { (sentido de industria vs. inferioridad) el cual consiste en } \\
\text { sobreponerse a la sensación de inferioridad que se le } \\
\text { demanda desde afuera al niño y que le confunde en su } \\
\text { actuar y uso de capacidades, así que se pone a prueba: "Yo } \\
\text { trato de olvidarlo, pues, la otra opción es hacerles caso, } \\
\text { porque quedan muy furiosos }[\ldots] \text { yo ya aprendí a hacer } \\
\text { caso. Si quiere pruébeme[....]". }\end{array}$ \\
\hline \multirow[t]{2}{*}{$\begin{array}{l}\text { Motivos de } \\
\text { consulta }\end{array}$} & $\begin{array}{l}\text { Juan: Las personas creen que yo soy cansón }[\ldots . .] \\
\text { yo no quisiera cambiar nada más, ya cambié } \\
\text { arto }[\ldots] \text { yo voy a tratar de no hablar tanto, } \\
\text { porque hablo mucho. }\end{array}$ & $\begin{array}{l}\text { Existen deseos de cambio influenciados por presiones } \\
\text { sociales externas de pares sociales o figuras de autoridad. }\end{array}$ \\
\hline & $\begin{array}{l}\text { María: Yo no sé criar al niño, yo veo que hay } \\
\text { mamás que sí saben cuidar los niños [...]. Yo } \\
\text { quiero mejorar mi forma de ser con él, también } \\
\text { las cosas malas que uno tiene }[\ldots . .] \text { yo quisiera } \\
\text { darle todo lo que él me pide }[\ldots] \text { él es muy } \\
\text { desobediente, no hace caso[...]. Yo sufro de } \\
\text { ataques epilépticos desde los } 16 \text { años }[\ldots . .] \text { es } \\
\text { que mi papá abusó de mí cuando era niña [...] } \\
\text { yo lo denuncié y desde ese momento se me vino } \\
\text { la familia encima }[. . .] \text { mi mamá no me quiere } \\
\text { [llanto] }[\ldots . . .]\end{array}$ & $\begin{array}{l}\text { María parece reconocer aspectos por mejorar en su } \\
\text { ejercicio de maternidad y de no saber que hacer frente } \\
\text { al comportamiento de Juan. Esto en el momento de la } \\
\text { consulta. Sin embargo, otras experiencias demuestran lo } \\
\text { contrario: } \\
\text { La tensión en la relación con el niño es presente en otros } \\
\text { espacios, la norma es difusa, pues se modifica de acuerdo } \\
\text { con el estado de ánimo de María, que fluctúa entre el } \\
\text { castigo físico o verbal y un discurso en el que manifiesta } \\
\text { deseos de cambio. Maier (61, 1971) al citar a Erikson, } \\
\text { refiere que el niño posee un sentimiento de inferioridad } \\
\text { por la edad y por la dependencia de la cual es objeto, } \\
\text { no obstante, los trata de resolver usando diligentemente } \\
\text { todas sus capacidades en el aprender haciendo y el uso } \\
\text { de potenciales. De acuerdo con lo citado, la relación con } \\
\text { la madre ofrece una ambivalencia: por un lado, el niño } \\
\text { valora la compañía y el soporte de funciones del contexto } \\
\text { familiar; por otro lado, la relación refuerza un sentimiento } \\
\text { de inferioridad que dificulta constantemente el uso de } \\
\text { oportunidades. }\end{array}$ \\
\hline $\begin{array}{l}\text { Las rupturas } \\
\text { familiares del } \\
\text { niño }\end{array}$ & $\begin{array}{l}\text { Juan (relatado por tallerista): Yo sí sé lo que es } \\
\text { no tener la familia, porque a mí me abandonaron } \\
\text { cuando tenía cuatro años en el Bienestar Familiar } \\
\text { y es lo peor que le puede pasar a un niño[...]. }\end{array}$ & $\begin{array}{l}\text { La peor experiencia de Juan a lo largo de su desarrollo } \\
\text { es la separación afectiva de su familia a los cuatro años. } \\
\text { Posterior a este momento sufre diferentes separaciones } \\
\text { afectivas. } \\
\text { La expresión: "Es lo peor que le puede pasar a un niño" } \\
\text { da a conocer la atribución que el niño le da al hecho. } \\
\text { De esta manera, Juan lo tiene presente y no desea repetir } \\
\text { la experiencia. Por lo tanto, a partir de ella genera } \\
\text { mecanismos defensivos para no volver a vivirla. Mencioné } \\
\text { varios a lo largo del análisis, el primero es la negación, } \\
\text { el segundo es la huida hacia adelante, el tercero es la } \\
\text { creatividad observada en su pasión por el dibujo y el arte; } \\
\text { y el último de ellos es la intelectualización. Cada uno } \\
\text { tiene una función: } \\
\text { 1) La negación permite no creer que se ha sufrido o se } \\
\text { sufre. } \\
\text { 2) Vigilante constantemente para que nos e repita la } \\
\text { experiencia. } \\
\text { 3) Experimentar el bienestar de la aprobación de su } \\
\text { habilidad imaginativa por medio del dibujo: Esta es una } \\
\text { actividad que caracteriza la personalidad de Juan y que le } \\
\text { reconocen las personas en su campo relacional. } \\
\text { 4) Le permite crear un espacio interno cognitivo para el } \\
\text { entendimiento del mundo por medio de las matemáticas, } \\
\text { facilitándole dominar la emoción insoportable (la tristeza) } \\
\text { en las dinámicas relacionales existentes. }\end{array}$ \\
\hline
\end{tabular}




\begin{abstract}
María: Cuando Juan tenía cuatro años, nos separamos Camilo (el papá de Juan) y yo. Yo en ese tiempo tenía muchos ataques y no me acordaba casi de las cosas [...] pero yo creo que la gente del barrio llamó a la Policía y se llevaron a Juan para el Bienestar porque dejábamos solo al niño [...] a mí también me dejaron vivir allá en el centro de madres, pude ver al niño una hora en las tardes, eso era ahí al lado donde él estaba [...]. A mí lo que me dijo una defensora era que a Juan lo iban a poner en adopción, entonces ahí lo que hizo mi mamá fue pedir la custodia del niño, pero primero se la dieron al papá, pero la señora que vivía con él le pegaba mucho al niño, entonces por eso le dieron la custodia a mi mamá [...]. Las cosas siempre estuvieron muy mal con mi mamá y ella no me dejaba ir casi allá a la casa de ella, porque nunca me perdonaron haber denunciado a mi papá, y como ella tenía la custodia no me dejó ver casi al niño, lo podía ver muy poquito [...]. Yo creo que allá lo trataban muy mal, porque mi mamá es muy templada [...]. Ya después de por ahí cuatro años que el niño estuvo con la abuela, Bienestar me dio el permiso para yo poderlo tener, porque yo ya estoy muy bien de salud y como vivo con Marcos hace un tiempo, ya el niño volvió a vivir conmigo.
\end{abstract}

Las separaciones afectivas suceden a partir de los cuatro años, en todas ellas ha existido el castigo físico y el uso de límites rígidos frente a la crianza de Juan.

El uso de una norma rígida y separaciones afectivas dificulta el afianzamiento de la norma social y la adaptación a los contextos sociales y normas familiares actuales.

\section{Resultados y conclusiones}

Desde el enfoque teórico en el que se inscribe la presente investigación, aparece que el proceso de la resiliencia requiere de tres condiciones fundamentales (Cyrulnick, 2003). Ellas serían: los recursos internos, el significado que se le da a la experiencia traumática y la disposición de recursos externos. Estos tres recursos son la base teórica sobre la cual se clasificarán las conclusiones (tres grupos). A continuación, se presentan los fragmentos y las consideraciones teóricas que permitieron poner en evidencia la existencia de cada uno de ellos y que harían de Juan un niño resiliente.

\section{Los recursos internos}

Juan tiene un temperamento resiliente que se demuestra en dos conductas básicas y dos aptitudes: la negación, la huida hacia adelante, la creatividad y la intelectualización. Estas cuatro son conocidas como mecanismos defensivos del temperamento del niño para transformar la experiencia dolorosa en algo soportable. Quizá por sí mismos, estos mecanismos defensivos solo sirvan para evitar la realidad del niño, pero articulados con la significación que se le da al hecho y el apoyo externo son el mejor aliado en el desarrollo del proceso resiliente:

1. La negación, contribuye a dejar atrás el sufrimiento, genera una flexibilidad en Juan que le permite aceptar las nuevas relaciones afectivas de su entorno de desarrollo, lo cual lo hace un niño sensible a los cambios de cuidador o cuidadora y una percepción de familia más extensa en la que existen diferentes roles que contribuyeron a su crianza y desarrollo. La separación afectiva que sucede con Juan a los cuatro años no le arrebata la posibilidad de afiliarse nuevamente a figuras afectivas, por el contrario, lo impulsa a vincularse y usar dichas relaciones para su desarrollo. La negación es un mecanismo de bloqueo que le dificulta tolerar el dolor y sufrimiento del devenir diario, pues le ha sido útil para experiencias traumáticas de sus primeros años de vida y continúa usándolo entre su repertorio de conductas para responder a los conflictos que surgen diariamente.

2. La huida hacia delante (hacia la acción) es un mecanismo defensivo usado por el niño para 
responder positivamente a casi todas las situaciones en las que percibe posibilidades de sufrimiento: tiene una conducta percibida por el contexto cultural y social como hiperactiva, con la que huye de temas y sensaciones relacionadas con el malestar, sufrimiento y sobre todo de la experiencia de separación inicial a los cuatro años de edad.

3. La creatividad en Juan es un aspecto de personalidad evidenciado principalmente en el dibujo. Tanto el niño como las personas que lo conocen en el ambiente educativo reconocen esta capacidad; el uso del dibujo provee a Juan de unos refuerzos positivos y el goce del bienestar de la aprobación para ejecutar esta habilidad como una práctica diaria en la que encuentra sentido.

4. Finalmente, la intelectualización es vivida por el niño a través de las aptitudes matemáticas. Sus habilidades lógicas le permiten transformar las experiencias de vulnerabilidad en un potencial de cambio, que al igual que la creatividad promueven la disposición de refuerzos positivos del medio cultural y proyectos personales para su desarrollo cognitivo y educativo.

A pesar del uso de los mecanismos defensivos mencionados, el niño, al no verse sin otros repertorios de respuesta, manifiesta profunda inseguridad y ansiedad producto tanto del momento evolutivo como del temor al cambio emocional de su madre o cualquier otra figura significativa. Esto sucede frente a diferentes intentos en el niño por cumplir tareas adaptativas del hogar, como tareas escolares, deberes en casa, puntualidad, entre otros, que no son fáciles de asimilar para Juan. En conclusión, la ansiedad es aparente ante llamados de atención de la madre que no están relacionados con el error, sino con una cadena de situaciones que vinculan la violencia, el reproche, el estado emocional de la madre, el castigo físico, el desprecio y el distanciamiento emocional.

La significación que se le atribuye al hecho Juan reconoce hechos de su vida con un alto impacto emocional para él. Esto podría darle el calificativo de hecho traumático, pues la experiencia en si misma podría haber sido percibida de otra forma. Sin embargo, el niño recuerda el hecho de separación de su familia (nuclear) como el "peor". La evidencia del relato es contundente, el malestar está nada más en lo verbal, pues sus capacidades evitativas le facilitan la manifestación del peor hecho de su vida, con aparente equilibrio emocional con el que proyecta un control y manejo personal significativo.

Este recurso de expresión sucedió en el espacio de participación social, mas no en el acompañamiento psicológico, lo cual permite identificar que el niño se afilia positivamente a otros espacios diferentes de la familia y el colegio en los cuales puede expresar abiertamente sus percepciones emocionales para su propio crecimiento y transformación de la experiencia adversa.

Este proceso expresivo en el niño no es común y tiene una gran utilidad pues le permite al medio social y cultural percibir al niño como un ser humano y disponer ayudas o "manos tendidas" (como lo diría Cyrulnick) para que el niño se logre "colar" en un contexto social y cultural más sensible y apropiado para la transformación.

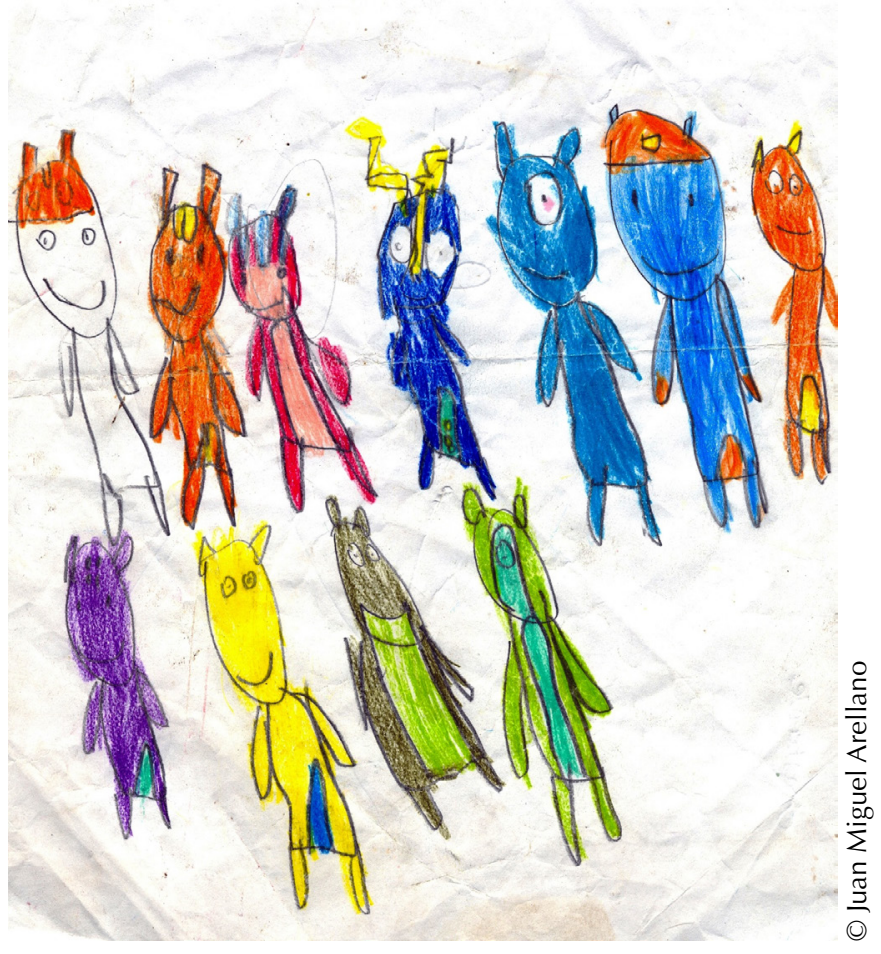


Disposición de recursos externos

A lo largo del desarrollo de Juan han existido diferentes recursos externos para fomentar el propio desarrollo. Cada uno de ellos parece insignificante por los vacíos de estimulación tan necesarios para cualquier niño, sin embargo, Juan toma de ellos las disposiciones necesarias y suficientes para sí mismo. El proceso de aprovechamiento de recursos es "maravilloso", pues las condiciones de estimulación no han sido "las mejores": Los cuatro primeros años en compañía de su padre y madre al interior de una estructura familiar nuclear abrieron caminos de estimulación fundamentales, el desarrollo del lenguaje estuvo acompañado del vínculo significativo y emocional con la madre y el padre que le dotó de un sentido de confianza básica en su infancia. La institucionalización en ICBF (Instituto Colombiano de Bienestar Familiar) y el paso por una familia reconstituida de su padre y una nueva cuidadora exigió de estrategias adaptativas muy superiores para la edad de cuatro años, sobrepasando la capacidad de apego inicial con su madre y que continuará sacando provecho de la separación afectiva que Juan refiere como "lo peor que le puede pasar a un niño". La convivencia en una familia extensa bajo el cuidado de su abuela durante cuatro años, las relaciones con primos de diferentes edades y tíos en casa le facilitó la percepción de una familia amplia (extensa y numerosa), la cual, se observa actualmente en sus dibujos y relatos ${ }^{1}$. Finalmente, el regreso de Juan a la convivencia con su madre biológica parece el final de una cadena de acontecimientos en los que la ruptura y la confusión emocional estuvieron presentes, pero que marcan situaciones que motivan nuevas manos tendidas a lo largo del proceso de crecimiento del niño.

El hospital y su grupo de participación social son espacios de expresión y convivencia nuevas para Juan que se generan a partir de su reintegro a la convivencia con la madre biológica a la edad de 10 años. Esto motivó nuevas dinámicas adaptativas que marcaron la experiencia en el hospital y grupo de liderazgo como una alternativa para la participación y nuevos espacios educativos más allá del colegio.

\footnotetext{
3 Ver matriz de análisis.
}

En cuestión de dos meses las actividades de participación se convierten en prioridad para Juan, las relaciones con las profesionales y talleristas de la oficina de participación social se fortalecen y sucede un evento altamente significativo para el desarrollo resiliente del niño: este evento consistió en el relato de la experiencia de institucionalización en el ICBF, la sensación de "abandono y la perdida de la familia" a sus cuatro años. Posterior a dicha manifestación se teje una red fundamental para el niño y la familia, que se compone de educación, recreación y sobre todo unos oídos dispuestos a acompañar al niño en sus experiencias, relatos y capacidades. En conclusión, este recurso externo es una "mano tendida" para aportar al uso de capacidades del niño y por ende a la metamorfosis del dolor.

El colegio, los amigos, la docente: tres actores que contribuyen especialmente en el fortalecimiento de aptitudes del niño y en la estimulación de otros aprendizajes no estimulados en otros momentos del desarrollo. En el momento de desarrollo del niño (industria vs. inferioridad) las capacidades productivas están en marcha y lo que produce es para su propio beneficio y formación. Por esta razón, los pares que ha logrado consolidar en el espacio del colegio son fundamentales para verificar sus propias habilidades y disminuir la sensación de inferioridad permanente que se refuerza en la relación con sus figuras cuidadoras quienes imponen valores culturales y normas que aún generan confusión en Juan.

\section{Referencias}

Bruner, J. (2013). La fábrica de historias. Madrid: Fondo de Cultura Económica de España.

Castañeda, P.; Guevara A. L.; (2005). Estudio de casos sobre factores resilientes en menores ubicados en hogares sustitutos. (Tesis de pregrado). Pontificia Universidad Javeriana. Recuperado de: http://www.javeriana.edu.co/biblos/tesis/ psicologia/tesis04.pdf

Cerda, H. (2007). La investigación formativa en el aula. La pedagogía como investigación. Bogotá: Magisterio.

Cyrulnick, B. (2001). La maravilla del dolor. El sentido de la resiliencia. Barcelona: Gránica.

Cyrulnick, B. (2006). Los patitos feos. La resiliencia: una infancia infeliz no determina la vida. Barcelona: Gedisa. 
Cyrulnick, B. (2003). Transcripción de entrevista a Boris Cyrulnik grabada en Santiago de Chile. Julio de 2003. Recuperado de: http://www. unabellezanueva.org/wpcontent/uploads/documentos/entrevista-boris-cyrulnik.pdf

Dolto, F. (1977). Psicoanálisis y pediatría. México: Siglo Veintiuno.

Gianino, L. (2012). La resiliencia en niños institucionalizados y no institucionalizados. Lima: Unifé. Recuperado de: http://www.unife.edu.pe/publicaciones/revistas/psicologia/2012/3/6 avances Igiannino 8.pdf

Guber, R. (2001). La etnografía: método, campo y reflexividad. Bogotá: Norma.

Gutiérrez, A. M.; Rafael, E. V. (2010). El efecto Pigmalión en la actividad docente y administrativa. Quipukamayoc, 17(33): 173-181. Recuperado de: http://sisbib.unmsm.edu.pe/bibvirtual/publicaciones/quipukamayoc/2010/V17n33-l/pdf/ a16v33n1.pdf
Heunneus, F. (1987). Una fundamentación científico natural del concepto de Gestalt. En: F. S. Perls. (Ed.). Esto es Gestalt. (pp. 277-293). San Joaquín: Cuatro Vientos.

Larrosa, J. (2000). Pedagogía profana. Estudios sobre lenguaje, subjetividad, formación. Buenos Aires; México: Novedades Educativas.

Maier, H. (1971). Tres teorías sobre el desarrollo del niño: Erikson, Piaget y Sears. Buenos Aires: Morrortu.

Santamaría, F. A.; Bothert, K. (2011). Relatos de niños y niñas: juegos de palabras que crean y recrean vivencias. Infancias Imágenes, 10(1): 66-73.

Obando, O. L.; Villalobos, M. E.; Arango, S. L. (2010). Resiliencia en niños con experiencias de abandono. Acta Colombiana de Psicología, 13(2): 149-159. Recuperado de: http://www. scielo.org.co/pdf/acp/v13n2/v13n2a13.pdf

Salazar, A. (1998). Interpreting and diverging in clinical interviews, Pragmatics, 8(2): 167-183.

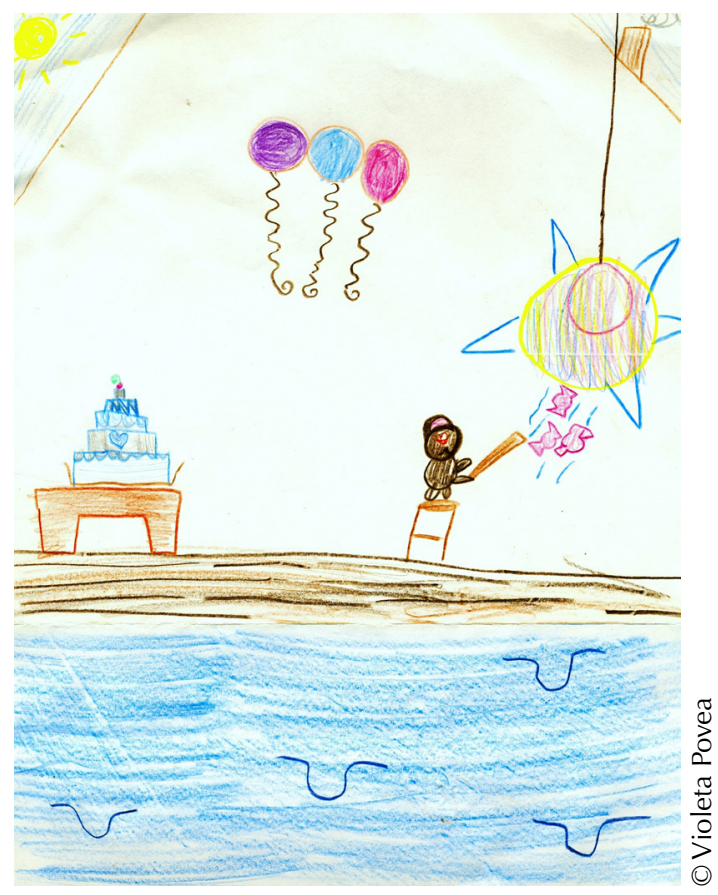

